\title{
RENAL BIOPSY AND GLOMERULONEPHRITIS
}

\author{
By J. H. Ross, M.D., M.R.C.P. \\ Senior Medical Registrar, The Connaught Hospital, and Assistant, The Medical Unit, \\ The London Hospital
}

\section{Introduction}

Safe methods of percutaneous renal biopsy were first described by Perez Ara (1950) and Iversen and Brun (195I) who used aspiration techniques. Many different methods have since been described; the simplest is that of Kark and Muehrcke (1954) who use the Franklin modification of the VimSilverman needle.

Brun and Raaschou (1958) have recently reviewed the majority of publications concerned with renal biopsy and have concluded that the risk to the patients is slight. They mentioned three fatalities which have been reported but considered that, in each case, death was probably due to the disease process rather than the investigation. Retroperitoneal haematomata have been recorded in patients with hypertension or uraemia but are unusual. Gross haematuria is uncommon (it occurred in 7.9 per cent. of 5 10 biopsy attempts by Brun and Raaschou, 1958, and 7 per cent. of 100 biopsy attempts by Muehrcke, Kark and Pirani, 1955). Pain in the loin following the procedure is also unusual. Although the procedure is simple, it should not be undertaken without careful instruction.

The contraindications observed by those experienced in renal biopsy have varied considerably. A haemorrhagic diathesis is, of course, an absolute contraindication. Patients with hydronephrosis, pyonephrosis, renal tuberculosis or neoplasm, very small kidneys, only one kidney or who are unable to cooperate, should not be submitted to the procedure. Most authors have considered uraemia a contraindication because of the associated haemorrhagic tendency, but Brun and Raaschou (1958) have not found any significant increase in the frequency of haematuria after biopsy in 119 uraemic patients and, in fact; consider acute uraemia of unknown aetiology to be an indication for the investigation.

Tissue, adequate for histological examination, can be obtained in about 75 per cent. of cases. The specimen may be regarded as representative of the kidney except in focal diseases such as pyelonephritis. Very small fragments of tissue may be sufficient to establish a diagnosis in a few condi- $\vec{\circ}$ tions such as amyloid disease and diabetic $\vec{\omega}$ glomerulosclerosis, but cortex with at least ro glomeruli is necessary for an accurate assessmento of the renal structure; occasionally, up to 403. glomeruli may be present in a single specimen. î

The revelation of gross structural changes in the kidneys of patients who can be recognized 8 clinically as having chronic glomerulonephritis is of little value and does not contribute to management or prognosis. In contrast, biopsy specimeng from patients in the early stages of glomerul $\vec{\Phi}-$ nephritis, particularly those who have developed the nephrotic syndrome insidiously withoo haematuria or renal failure or who show no evidence of disease other than proteinuria, may provide useful information. The value of histo $\vec{\theta}$ logical study in such cases is, however, limited by the interpretation of the significance of minf non-specific lesions. Insufficient time has passed since the introduction of renal biopsy to allow many conclusions to be drawn as to the correlation between such histological features and the subsequent progress of the patients.

The application of renal biopsy to the study of $\overline{\bar{a}}$ glomerulonephritis will be discussed in this article; many references to its use in other renal diseases may be found in the review by Brun and Raaschou (1958).

\section{The Nephrotic Syndrome (Type II Nephritis)}

Variations in terminology and diagnostic criteria, as with so much of the literature of renal disease, have made it difficult to compare the results of different workers, especially when full case reports

have not been presented.
The term 'nephrotic syndrome' was first in- 을 troduced by Leiter in I93 I to differentiate the $N$ association of massive proteinuria, oedema, hypoproteinaemia and hypercholesterolaemia with $\mathcal{O}$ renal disease such as glomerulonephritis from $\omega$ 'lipoid nephrosis' which was considered to have the same four features without hypertension, nitrogen retention, an excess of red blood cells in $\mathbb{D}$ the urine or histological glomerular lesions. 


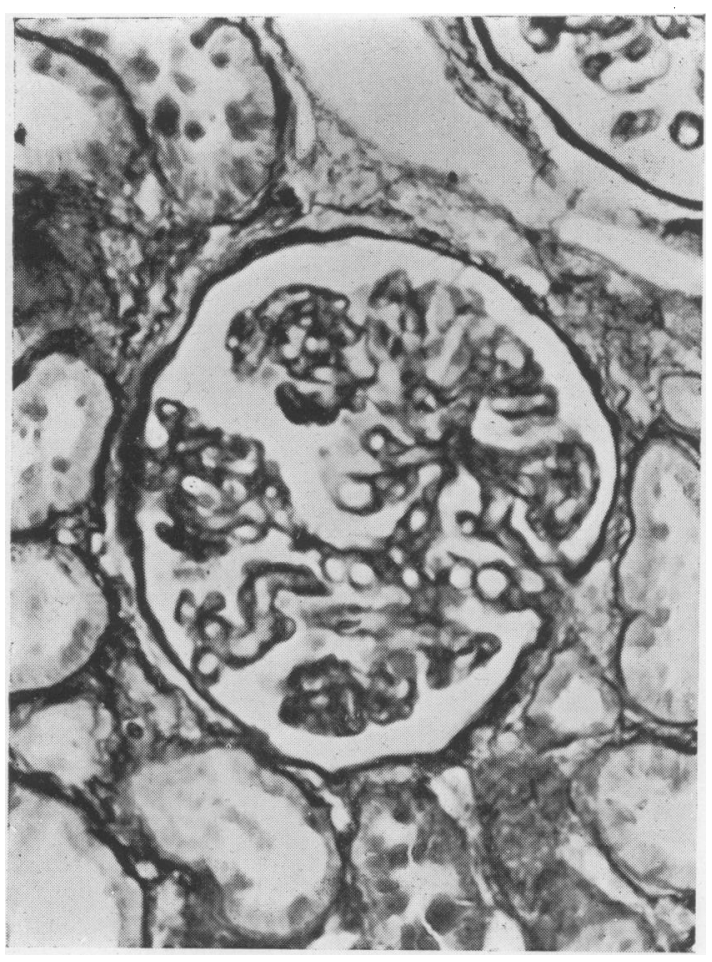

Fig. 1.-Glomerulus with diffuse basement membrane thickening. This feature was present in all of 15 glomeruli in the specimen from a man aged 52 years with the nephrotic syndrome of seven months duration. Renal failure and hypertension have developed. Heidenhain's Azan stain, $\times 310$.

'Nephrotic syndrome' is not a diagnosis in itself and should always be qualified by the associated disease process or aetiological agent if these can be recognized clinically or histologically (Kark et al., 1958, listed 3 I possible causes of the syndrome). The condition, when no cause has been identified, has been variously termed 'type II nephritis,' ' lipoid nephrosis,' the ' uncomplicated ' or 'idiopathic' nephrotic syndrome or has been given a histological label according to the school of thought of the observer. In this article, type II nephritis will be the name used whether the fully developed lesions described by Ellis in 1942 (the membranous or lobular glomerulonephritis of Allen, I95I and 1955) are shown to be present or not.

Amyloid disease may occasionally be revealed unexpectedly by biopsy in patients considered clinically to have early type II nephritis (Bjornoboe et al., 1952; Ross and Ross, 1957). This finding suggests a worse prognosis and may prevent valueless treatment with steroids.

Patients with early type II nephritis, whose clinical features are similar, may be found to have strikingly different histological lesions. Glomeru- lar lesions at present give the best indication of the subsequent progress which may be expected, but further study may reveal the significance of minor tubular and interstitial features. The finding of generalized basement membrane thickening (Fig. I) or intercapillary hyalinization in the glomeruli probably indicates that recovery is impossible and that progress to renal failure with hypertension, even though it may be delayed for many years, is inevitable; the use of steroids for the treatment of patients with these lesions is usually disappointing. The recognition of small increases in basement membrane thickening is, however, difficult and; in addition, Rich (1957) has shown, in necropsy specimens, that the lesions may be more pronounced in the juxtamedullary zone than in the outer cortex; such considerations may cast doubt on the interpretation of some small specimens.

The interpretation of minor focal lesions in the kidneys of these patients is even more difficult. Increase in tuft cells, basement membrane thickening, intercapillary hyalinization and capsular adhesions are found diffusely or locally in occasional glomeruli but are not generalized (Bjornoboe et al., 1952; Kark et al., 1955; Ross and Ross, 1957; Joekes et al., 1958). Recovery from the disease is still possible and the severity of the lesions may give some indication of the subsequent progress of the patient; conclusions beyond these are not yet possible. There has been only one report of serial biopsies demonstrating that such minor lesions precede generalized basement membrane thickening (Joekes et al., 1958) but circumstantial evidence suggests that this may be a frequent structural sequence. It seems unlikely that any small structural differences in these cases will be recognized by conventional microscopy which will allow the histologist to foretell recovery, a long benign course or progress to renal failure.

Some biopsy specimens from these patients show no glomerular lesions at all; again, recovery may occur but cannot be foretold with certainty. Prolonged follow-up of a large number of patients is necessary before more definite conclusions can be reached. Electron microscope studies (Farquhar et al., I957 a, b and c; Folli et al., 1958; Brun and Raaschou, 1958) have shown that an abnormality of the glomerular epithelial cells may be found in biopsy specimens from patients with early type II nephritis (the authors used different nomenclature) even when conventional microscopy has revealed no abnormalities. The characteristic ' foot processes' of normal epithelial cells (podocytes) disappear and the epithelial cytoplasm becomes closely applied to the basement membranes of the capillary loops. This change has not been noted in acute nephritis but it is still not clear 


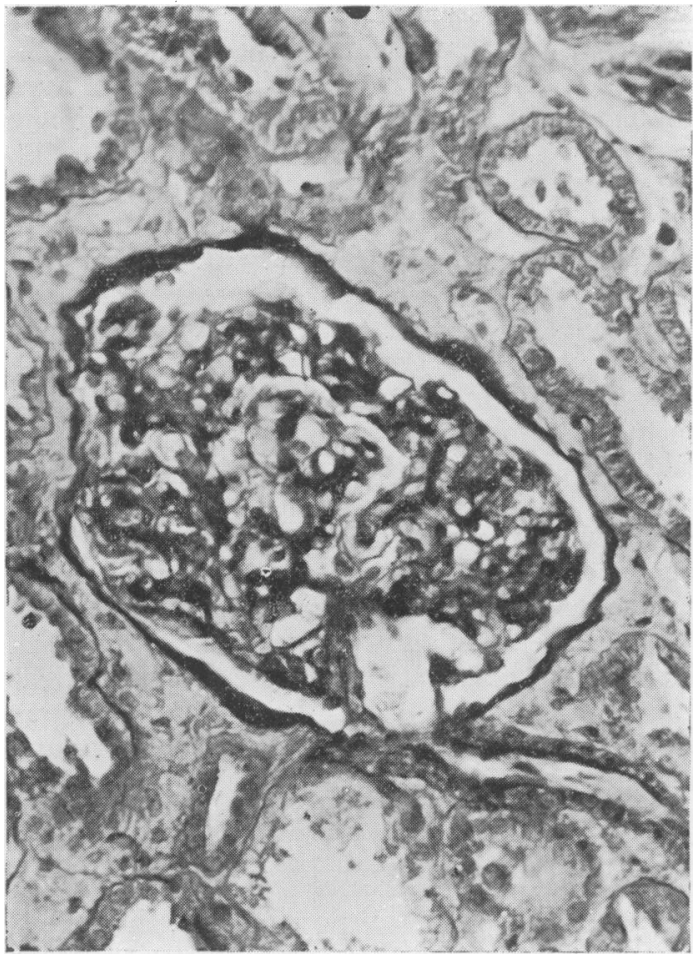

Fig. 2.-Case I. One of the most severely affected glomeruli in the specimen, showing intercapillary hyalinization and capsular adhesion. Periodicacid-Schiff stain, $\times 330$.

if its recognition can be used to differentiate a particular variety of nephritis or if it has any special functional significance. Folli et al. (1958) reported reversal of this lesion with recovery of a patient from the nephrotic syndrome; they used the diagnosis 'lipoid nephrosis' for patients with electronmicroscopic podocyte lesions but without membranous glomerulonephritis.

The following case notes illustrate some of the points which have been discussed.

\section{Case I}

A woman of $5^{\mathrm{I}}$ years developed the nephrotic syndrome without hypertension or nitrogen retention. A biopsy specimen, obtained two months after the onset of oedema, contained 18 glomeruli; one was completely hyalinized but the majority showed only slight hypercellularity with occasional increase in intercapillary material and a few capsular adhesions (Fig. 2). The tubules were normal and there was no increase in interstitial tissue. She was treated with mercurial diuretics without response but had a large diuresis whilst receiving an ion-exchange resin. Four months after the biopsy she was free from oedema; proteinuria dis-

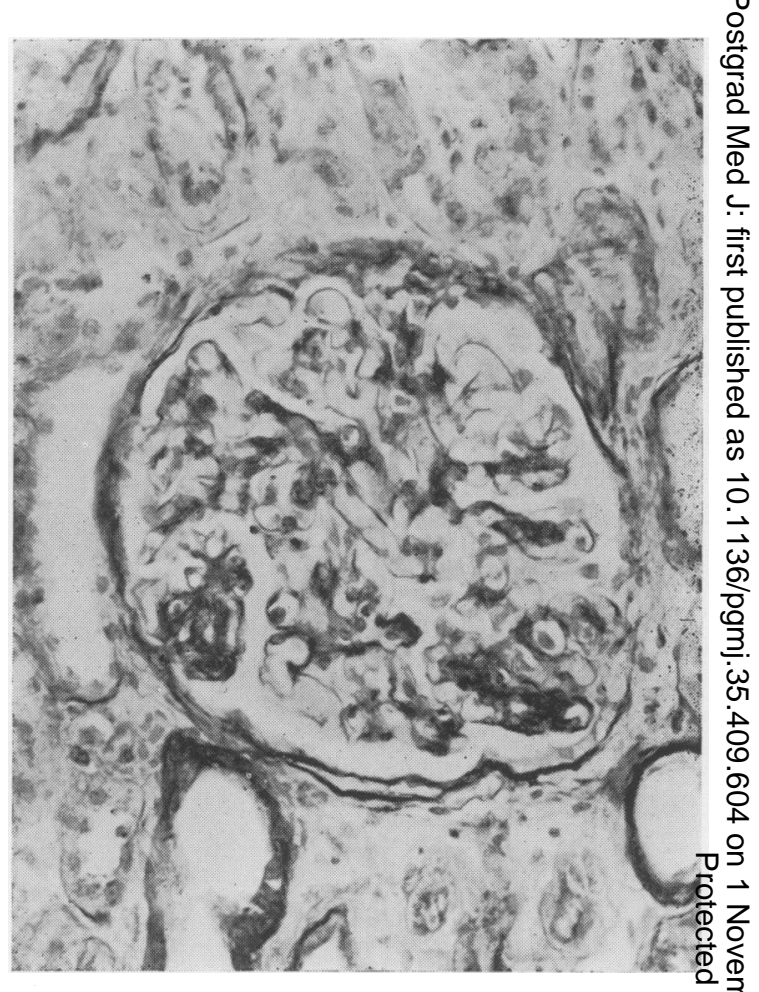

Fig. 3.-Case 2. Glomerulus with small areas of base ment membrane thickening and intercapillaro hyalinization adherent to Bowman's capsule $\overrightarrow{0}$ Periodic-acid-Schiff stain, $\times 330$.

appeared after another four months and she has remained well for a further i I months.

\section{Case 2}

A woman of $6_{5}$ years, known to have had benign $\overline{\mathrm{c}}$ essential hypertension without proteinuria previously, developed the nephrotic syndrome without impairment of renal function tests. A biopsy specimen, obtained 17 months later, contained 28 glomeruli; the majority showed minor lesions, as in Fig. 3. There was slight tubular atrophy and diffuse collagenous increase of the interstitial tissue. Oedema persisted for many months but had disappeared and there was only very slight proteinuria i9 months after biopsy, when she unfortunately died from causes unrelated to her renal disease.

\section{Case 3}

A Pakistani seaman, aged 4I years, developed ${ }_{N}^{N}$ gross proteinuria and oedema with hypertension but without haematuria. Six months after the onset his renal function was normal (blood urea $31 \mathrm{mg}$./100 ml., maximum urine urea concentration 25.2 g./l., creatinine clearance $98 \mathrm{ml}$./min.). 
When a biopsy specimen was obtained two months later there was moderate renal failure (blood urea $60 \mathrm{mg}$./100 ml., maximum urine urea concentration $13.2 \mathrm{~g} . / 1$., creatinine clearance $34 \mathrm{ml} . / \mathrm{min}$.). I4 enlarged hypercellular glomeruli had many small areas in the tufts which were adherent to Bowman's capsule and contained increased intercapillary material and thickened capillary basement membranes. There was diffuse collagenous increase of the interstitial tissue and many convoluted tubules were dilated and lined by ragged vacuolated cells. The lesions of the tubules may have been related to potassium depletion present at the time of the biopsy.

The glomerular lesions in this case were similar to those in cases $I$ and 2 but were more intense and could be correlated with the more severe clinical features of the disease. When the patient was last seen, Io months after the biopsy, renal failure was far advanced.

\section{Case 4}

A renal biopsy specimen was obtained from a boy aged nine years who had had the nephrotic syndrome for three and a half years with slight occasional hypertension but without haematuria or impairment of renal function. Immediately prior to the biopsy, a massive diuresis, accompanied by diminution in proteinuria, followed a course of ACTH. Treatment with prednisone was continued until seven months after the biopsy, when he lost proteinuria and was well in every respect.

The specimen contained I 4 glomeruli, four of which were completely hyalinized. The remainder were normal apart from occasional capsular adhesions and a few small areas containing increased cells and intercapillary material or slight basement membrane thickening. The tubules were normal but there was slight diffuse interstitial fibrosis.

These findings were of particular interest, demonstrating that recovery can occur in spite of focal glomerular hyalinization. It is possible that the higher recovery rate in children with type II nephritis is due to the disease remaining focal. Prolonged observation is necessary before recovery can be considered complete, as relapses have been reported many months or years after loss of proteinuria (Rennie, 1947; Roscoe, 1956).

\section{Case 5}

A woman, aged 49 years, developed the nephrotic syndrome which persisted, with intermittent gross oedema, for four years and then resolved completely. She has remained well, without proteinuria, for a further five years. Raised blood pressure, present during and since the disease, has

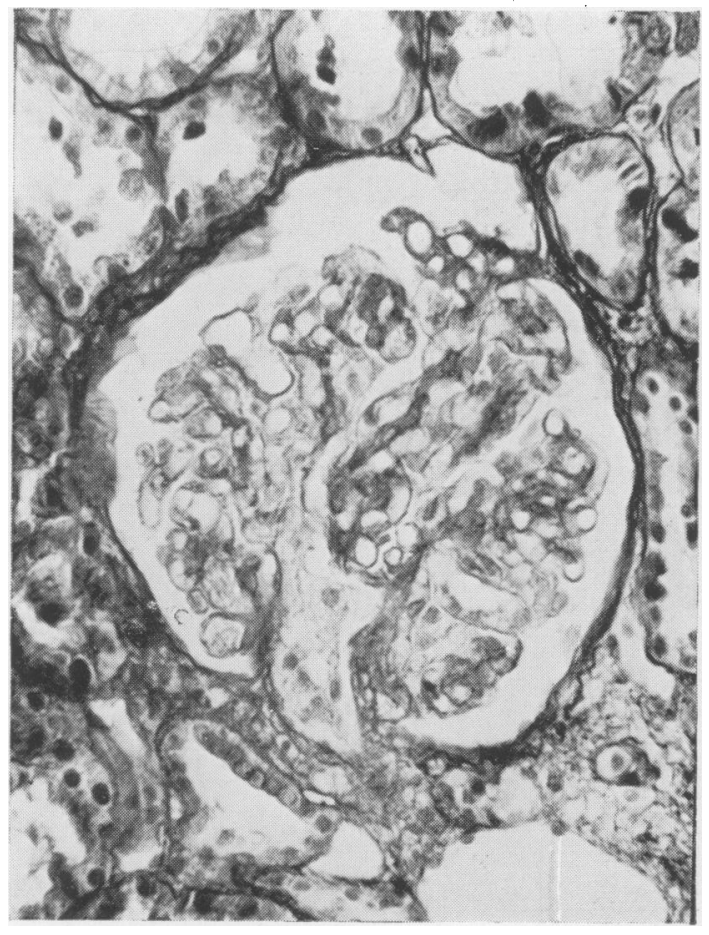

FIG. 4.-Case 5. Glomerulus which is normal apart from capsular adhesion and very slight adjacent hyalinization. Heidenhain's Azan stain. $\times 370$.

been considered to be due to benign essential hypertension.

A renal biopsy specimen was obtained three years after proteinuria had ceased. There were no abnormalities in the eight glomeruli examined apart from a few capsular adhesions associated with slight focal increase in intercapillary material (Fig. 4). There were no tubular abnormalities but there was very slight focal interstitial fibrosis.

The abnormalities in the glomeruli of this small specimen were considered to be the healed remains of focal glomerular lesions. It is much more likely that diffuse basement membrane thickening had never developed, even after four years of the disease, rather than that it had been present and had resolved.

\section{Case 6}

A man of 34 years was found to have heavy proteinuria when he attended hospital with a complaint of backache. He had never had oedema, his blood pressure was normal and renal function tests were unimpaired. A biopsy specimen showed ro of 17 glomeruli to be completely hyalinized; the remainder had diffuse basement membrane thickening and patchy intercapillary hyalinization 


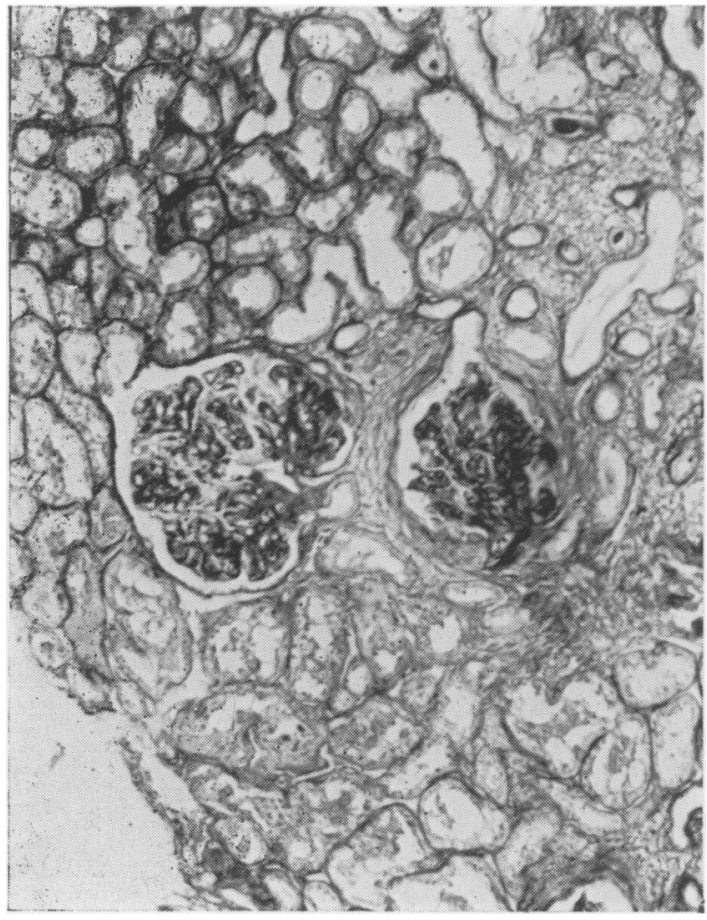

FIG. 5.-Case 6. Glomeruli with basement membrane thickening and intercapillary hyalinization. Focal tubular atrophy and dilatation. Interstitial fibrosis. Periodic-acid-Schiff stain, $\times$ roo.

(Fig. 5). There was focal tubular atrophy and dilatation as well as interstitial fibrosis.

This illustrates the value of renal biopsy in patients with proteinuria of obscure origin, for the lesions were those of fully developed type II nephritis and indicated a poor prognosis with eventual renal failure.

\section{Acute (Type I) Glomerulonephritis}

Hutt et al. (1958) have studied renal biopsy specimens from 15 patients diagnosed clinically as having acute glomerulonephritis (three had no proteinuria or haematuria). They found a reasonable correlation between the severity of the clinical and of the histological features. The glomerular tuft lesions were those which have been described previously in post-mortem material but the three atypical cases mentioned above only had minor changes in the cells of Bowman's capsule. Impairment of renal ability to concentrate was correlated with the severity of the tubular lesions.

Brun et al. (1958) obtained biopsy specimens from 9 to 49 days after the onset of symptoms in 13 patients with acute glomerulonephritis. Again, there was a good correlation between the clinical

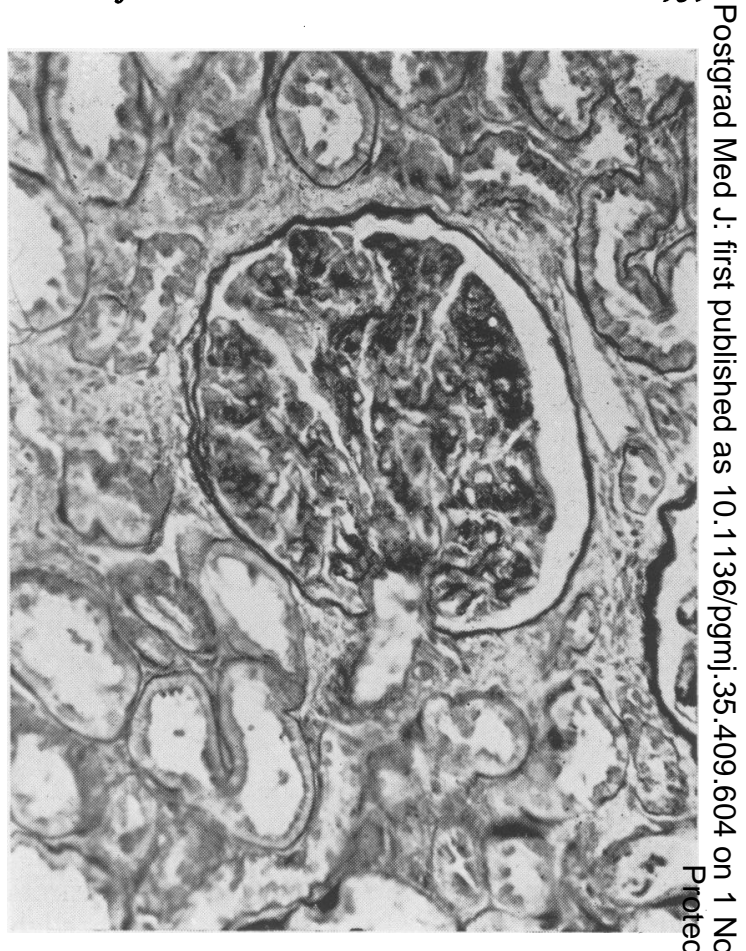

FIG. 6.-Glomerulus with intercapillary fibrillar $\mathrm{m}$ ब terial. The specimen, from a man of 47 years, wass taken during recovery from acute nephritis whist proteinuria and impairment of renal function tesps were still present. Four months later he was well $\vec{c}$ in every respect. The glomeruli were also hypex:cellular with a slight excess of polymorphonuclesin. leucocytes in the tufts and there was focal perivas cular fibrosis. Periodic-acid-Schiff stain, $\times 230$.

and histological features. The finding of generalized $\stackrel{\varrho}{\varnothing}$ 'irreversible' changes in the glomeruli was con- $\varrho$ sidered to indicate a hopeless prognosis in six $\overrightarrow{\overrightarrow{0}}$ cases. The authors were surprised to observe 3 ' chronic' collagenous glomerular lesions in some specimens; these may have been due to previous? renal disease or it is possible that such lesions 흘 develop more rapidly than was previously thought possible.

The demonstration of intense inflammatory and necrotic lesions in the kidneys of patients with severe acute nephritis is not unexpected. It will be of more value if structural changes can be 을 recognized which will allow differentiation between $\frac{D}{2}$ mild cases who will recover and mild cases who will progress slowly to renal failure. Hutt et al. (1958) N obtained one specimen six weeks after the onset of oedema and haematuria and about four weeks 0 after recovery had commenced; only slight pro- $\omega$ liferative changes and a patchy increase of periodic -2 acid-Schiff staining fibrils were present in the glomeruli. The author has observed similar $\$$ lesions in specimens from two patients recovering ${ }^{+}$ 


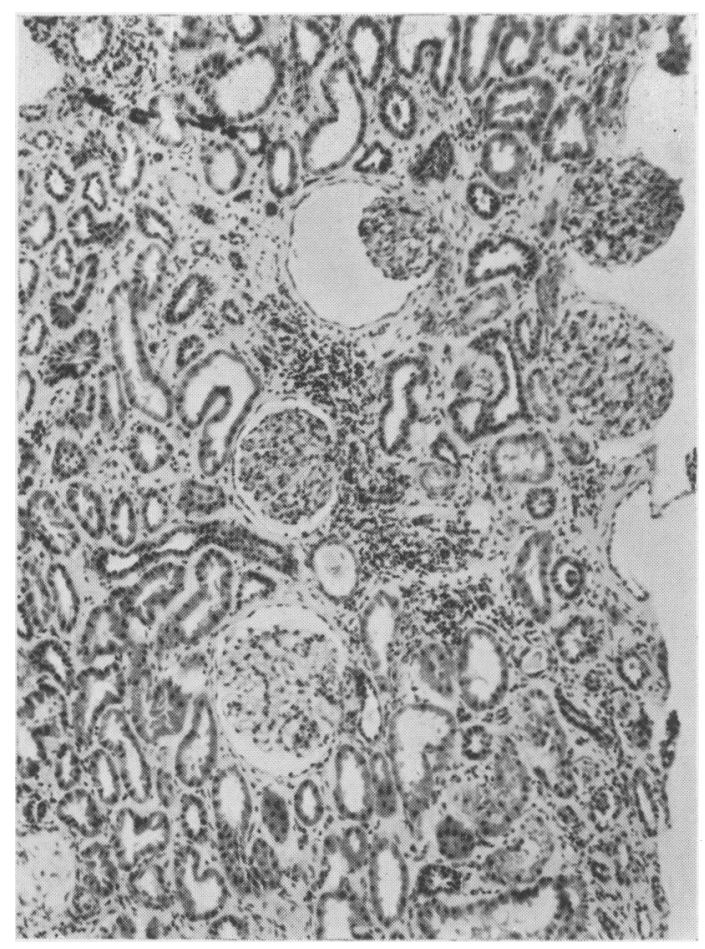

FIG. 7.-Part of specimen from a boy aged 15 years who had had at least six attacks of haematuria during the 18 months preceding biopsy. There is increase of interstitial tissue with focal chronic inflammatory cell infiltration and two glomeruli show ischaemic changes with shrunken tufts and thickened capsules. Haematoxylin and eosin, $\times 100$.

from the acute stage of the disease (Fig. 6); one of them has made a complete recovery, the other still has slight proteinuria one year after biopsy. Perhaps the finding of collagenous glomeruli or diffuse interstitial fibrosis will be correlated with failure to recover and a slowly progressive course, when more patients have been studied.

Farquhar et al. (1957 b and c) have described the electronmicroscopic glomerular lesions in acute glomerulonephritis. In the early stages the hypercellularity was found to be mainly due to an increase in the number of the endothelial cells. The cytoplasm of both epithelial and endothelial cells was swollen but the foot processes were normal except in severely affected areas. Material resembling basement membrane substance and believed to originate from endothelial cells accumulated within the tufts; this is probably the material forming the P.A.S. fibrils seen on conventional microscopy and which may accumulate sufficiently to form ' hyaline' glomeruli.

\section{Focal Glomerulonephritis}

Bates et al. (1957) described renal biopsy

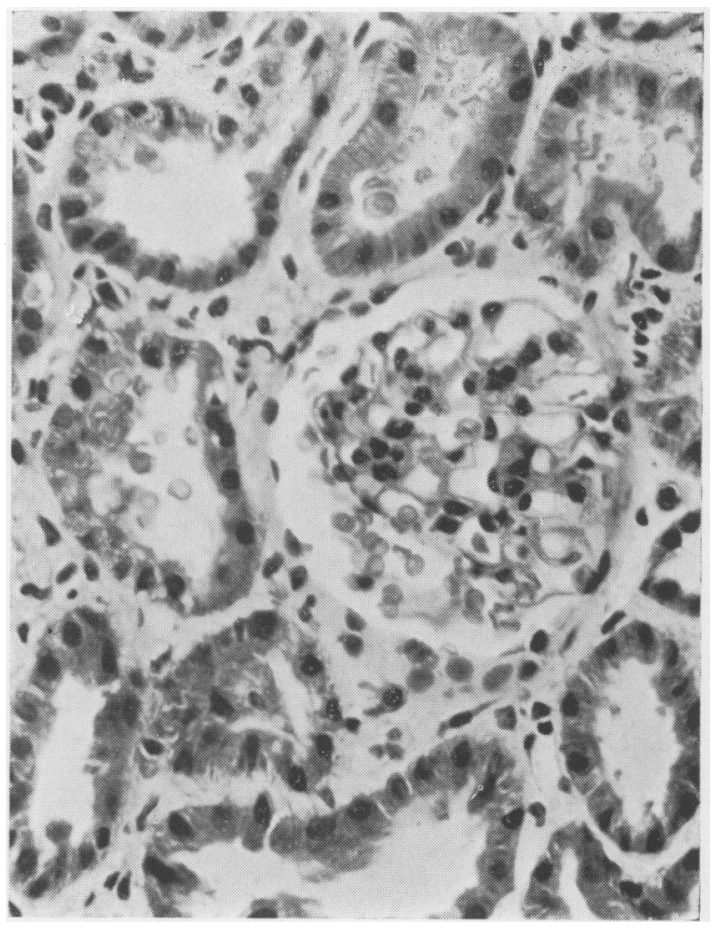

FIG. 8.-Another part of the specimen shown in Fig. 7. Glomerulus with capsular adhesion. Red blood cells in capsular space and in adjacent convoluted tubules. Increase of interstitial tissue. Haematoxylin and eosin, $\times 410$.

specimens from nine patients with very mild nephritis associated with acute pharyngitis. Clinical and immunological studies excluded recent group A haemolytic streptococcal infection and haematuria alone was the predominant feature of the disease. The glomerular lesions were mild and focal and were contrasted with the more severe proliferative lesions observed in specimens from patients with typical acute nephritis following group A haemolytic streptococcal infections. The mild disease was presumably acute 'focal nephritis' occurring at the height of an unidentified infection.

Ross (1959) has studied five specimens from nine patients with recurrent focal nephritis. This unusual disease, which occurs in young patients, is characterized by repeated attacks of haematuria without oedema, hypertension or nitrogen retention. Following a number of attacks, which can be initiated by a variety of infections, proteinuria may persist. Renal function remains normal even after many years. The glomerular lesions are focal and consist of small areas in the tufts containing increased cells and intercapillary material with associated adhesions to Bowman's capsule. Intersti- 
tial inflammation also occurs and after repeated attacks the structural damage may be quite severe (Figs. 7 and 8). Long-term treatment with penicillin and short courses of steroids have not been found to prevent or shorten the attacks of haematuria.

\section{Conclusions}

Renal biopsy may occasionally be a considerable aid to diagnosis and prognosis in individual patients with glomerulonephritis. Frequently, however, the lesions revealed are either those that might be expected from a study of the clinical features or are insufficiently specific to give information of immediate value to the clinician. Further detailed studies with prolonged observation of the patients and the new techniques of electronmicroscopy, histochemistry and antigenantibody reaction localization (Mellors and Ortega, 1956) should lead to knowledge which will increase the value of the procedure.

\section{Acknowledgments}

I am grateful to Professor Clifford Wilson and Professor Dorothy Russell for permission to quote cases studied at the London Hospital and to reproduce microphotographs prepared in the Bernhard Baron Institute of Pathology.

\section{BIBLIOGRAPHY}

ALLEN, A. C. (1951), 'The Kidney: Medical and Surgicalo Diseases,' Grune and Stratton, New York, Ist ed.

ALLEN, A. C. (1955), Amer. F. Med., 18, 277.

BATES, R. C., JENNINGS, R. B., and EARLE, D. P. (1957), Ibid., 23, 5 10.

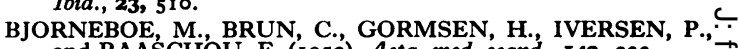
and RAASCHOU, F. (1952), Acta. med. scand., 142, 233. BRUN, C., GORMSEN, H., HILDEN, T., IVERSEN, P., and RAASCHOU, F. (1958), Ibid., 160, 155.

BRUN, C., and RAASCHOU, F. (1958), Amer. F. Med., 24, 676.

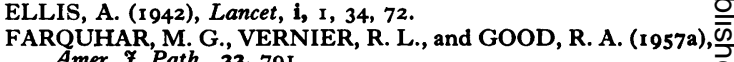
Amer. $\mathcal{F}$. Path., 33, 791.

FARQUHAR, M. G., VERNIER, R. L., and GOOD, R. A. (1957b), Schweiz. med. Wschr., 17, 50 .

FARQUHAR, M. G., VERNIER, R. L., and GOOD, R. A.ळ (1957c), Ұ. exp. Med., 106, 649.

FOLLI, G., POLLAK, V. E., REID, R. T. W., PIRANI, C. L., $\vec{\circ}$ and KÄR, R. M. (1958), Ann. intern. Med., 49, 775.

HUTT, M. S. R., PINNIGER, J. L., and DE WARDENER, H. E.w (1958), Quart. F. Med., 27, 265.

IVERSEN, P., and BRUN, C. (I951), Amer. F. Med., II, 324.

JOEKES, A. M., HEPTINSTALL, R. H., and PORTER, K. A. (1958), Quart. F. Med., 27, 495.

KARK, R. M., and MUEHRCKE, R. C. (1954), Lancet, i, 1047. KARK, R. M., MUEHRCKE, R. C., PIRANI, C. L., and POLLAK, V. E. (I955), F. clin. Invest., 34, 944 .

KARK, R. M., PIRANI, C. L., POLLAK, V. E., MUEHRCKE, R. C., and BLAINEY, J. D. (1958), Ann. intern. Med., 49, 751 . LEITER, L. (193I), Medicine (Baltimore), 10, 135.

MELLORS, R. C., and ORTEGA, L. G. (1956), Amer. F. Path.,, 32, 455 . MUEHRCKE, R. C., KARK, R. M., and PIRANI, C. L. (1955),
F. Urol., 74, 267.

PEREZ ARA, A. (1950), Bol. Liga Cáncer (Habana), 25, 121.

RENNIE, J. B. (1947), Quart F. Med., 16, 21.

RICH, A. R. (1957), Bull. fohns Hopk. hosp., 100, 173.

ROSCOE, M. H. (1956), Quart. F. Med., 25, 253.

ROSS, J. H., and ROSS, I. P. (r957), Lancet, ii, 559.

ROSS, J. H. (1959), publication in preparation.

\section{NOTICE OF SPECIAL INTEREST TO SUBSCRIBERS:}

\author{
-WHY NOT HAVE YOUR COPIES OF THIS \\ JOURNAL BOUND INTO YEARLY VOLUMES?'
}

You can have your twelve monthly issues fully bound in dark green pin head doth. lettered in gilt on spine with name of Journal, Volume Number and year, complete with index at front, for 22s. 6d. post free. A limited number of out of prine fournals are available to bind into volumes and make your library complete. Price on application siving details of issues required to complete back volumes.

THE FELlOWSHIP OF POSTGRADUATE MEDICINe 60 PORTLAND PLACE, LONDON, W.I

\section{WHY NOT HAVE YOUR JOURNALS BOUND?}

Bibliography continued from page 603-A. A. G. Lewis, B.Sc., M.D., M.R.C.P.

SMITH, HOMER W. (1956), 'Principles of Renal Physiology,' New York, O.U.P. SMITH, HOMER W. (1958), Bull. N.Y. Acad. Med., 35, 293. REUBI, F. (1958), Helvet. med. Acta, 25, 516. RHODIN, J. (1958), Amer. F. Med., 24, 66r.

TRUETA, J., BARCLAY, A. E., DANIEL, P. M., FRANKLIN, K. J., and PRICHARD, M. M. L. (I947), 'Studies of the Renal Circulation,' Oxford, Blackwell.

ULLRICH, K. J., and JARAUSCH, K. H. (1956), Pflug Archiv. ges. Physiol., 262, 537.
VANDER, A. J., MALVIN, R. L., WILDE, W. S., and SULLIVAN, L. P. (1958), Amer. ऊ. Med., 25, 497.

WALKER, A. M., BOTT, P. A., OLIVER, J., and MAC-N DOWELL, M.' (1941), Amer. F.'Physiol., I34, 580. DE WARDENER, H. E., and HERXHEIMER, A. W. (1957),,$\omega$
J. Physiol., r39, 42.

WINTON, F. R. (1956), in 'Modern Views on the Secretion of the Urine,' London, Churchill. WIRZ, H. (r954), in the Ciba Foundation Symposium on the

WIRZ, H. (1956), in 'The Neurohypophysis,' London, Butter-? worth's Scientific Publications. 